\title{
Trabajo y salud en los años de la reestructuración productiva. El caso de los trabajadores de la ex Propulsora Siderúrgica, Ensenada, Buenos Aires ${ }^{1}$
}

\author{
María Alejandra EsPonda
}

resumen En este artículo analizamos las construcciones de los trabajadores respecto de su cuerpo, salud, enfermedades y accidentes laborales en relación con el trabajo, el lugar y las condiciones de trabajo en una gran empresa siderúrgica en el marco de la restructuración productiva. Vamos a analizar como están atravesadas por dos cuestiones principales, ambas marcadas por contradicciones y ambivalencias: por un lado lo que atañe al trabajo como actividad vital y constitutiva del sujeto, que compromete su corporalidad y lo valoriza en tanto trabajador; y por otro lado el trabajo como relación política entre obreros, delegados fabriles, patrones y sindicato, que expresa luchas de poder en el lugar de trabajo. Ambas cuestiones complejizan la manera en que los trabajadores conciben su propia salud y su cuerpo, comprensible en tanto la consideremos como experiencia histórica, económico-política, ideológica y cultural amplia.

palabras clave Trabajadores. Reestructuración productiva. Siderurgia. Cuerpo. Salud.

\section{Introducción}

En este artículo profundizamos en las construcciones respecto de la relación entre trabajo, cuerpo y salud, en el marco de las transformaciones e impactos de la desindustrialización sobre la clase trabajadora industrial desde el punto de vista de trabajadores de una gran empresa siderúrgica, ex Propulsora Siderúrgica actual Siderar - Planta Ensenada (Buenos Aires, Argentina) perteneciente al Grupo Techint ${ }^{2}$.

Nos proponemos contribuir a problematizar la salud-enfermedad de los trabajadores como una construcción social, al incluir los procesos ideológicos-culturales y políticos que los constituyen (Grimberg, 1997), ya que lejos de concepciones biologistas, consideramos que estas construcciones surgen enteramente de su inserción en un proceso histórico y social (Menéndez, 1990).

Partiendo de la idea de que las construcciones que los trabajadores realizan sobre el proceso salud-enfermedad, expresan contradicciones inherentes a la relación capital-trabajo, y se pueden explorar en múltiples dimensiones, en este trabajo nos vamos a centrar en un aspecto fundamental relevado en nuestro material de campo, y que tiene que ver con la percepción hegemónica del cuerpo en tanto medio para transformar la naturaleza y potencial fuerza de trabajo dispuesta para el trabajo y la productividad, a partir de la cual la medicina científica construyó su discurso sobre el cuerpo, la salud y la enfermedad (Alves, 2004; Menéndez, 1986).

En este sentido los trabajos de Dejours dan cuenta de varios aspectos de esta relación, entre ellos: a) que la reticencia de los trabajadores a 
hablar sobre la enfermedad y reconocerla, tiene que ver con su vinculación a la incapacidad laboral; b) que no hay placer en el trabajo que no pueda obtenerse sin dialéctica con la angustia al analizar la relación entre proceso y relaciones de trabajo, placer y sufrimiento. Esto nos remite a la significación del trabajo no sólo como medio de subsistencia sino como relación con uno mismo en la que a la vez que incrementa la subjetividad, constituye la fuente del reconocimiento por parte del otro. En el campo de lo social, el trabajo es el mediador fundamental para obtener el reconocimiento de la contribución de cada uno a la sociedad y la construcción de la identidad individual y colectiva (Dejours, 2000 y 1988).

Sin embargo, esta relación con el propio trabajo está inscripta en relaciones de dominación, en la que los cuerpos de los trabajadores son apropiados y expropiados para la producción capitalista, fortaleciendo la asociación entre salud y riqueza, fortuna; y enfermedad y desgracia, miseria (Minayo, 1992, apud Canesqui, 2003).

El artículo está estructurado de la siguiente manera: un primer apartado donde realizamos una breve introducción a las transformaciones económico políticas que se sucedieron a nivel global a partir de mediados de los años 70, centrando nuestra mirada en Latinoamérica y especialmente en Argentina, para ver cómo éstas afectaron a la clase trabajadora. En un segundo apartado retomamos las nociones sobre los tres cuerpos (individual, social y politico) de Scheper-Hughes \& Lock (1987), para pensar la relación con el proceso histórico concreto, y cómo el cuerpo y la salud de los trabajadores fueron observados e intervenidas por el poder económico y político en diversos momentos y afectando diferentes dimensiones ${ }^{3}$. En un tercer apartado indagamos cómo el "trabajo", en tanto espacio de construcción subjetiva e intersubjetiva de relaciones sociales y de poder, es útil para pensar en diferentes aspectos de esas relaciones paradójicas y conflictivas. En el cuarto apartado exploramos esas relaciones a partir de narrativas sobre condiciones de trabajo, enfermedades y accidentes laborales.

\section{Hegemonia neoliberal, desindustria- lización e impactos sobre la clase trabajadora}

La hegemonía del neoliberalismo a nivel mundial, se remite hacia finales de la década del 1970, aunque la crisis estructural del capital (Antunes, 2005) comenzó a visibilizarse algunos años antes (Harvey, 1998). Entendiendo la crisis capitalista como señal de ruptura de un patrón de dominación de clase relativamente estable, que se expresa en la caída de la tasa de ganancia, la única manera de encontrar una resolución para el capital radicó en la imposición de nuevos patrones de dominación (Holloway, apud Antunes, 2005).

La reducción de "costos" de producción se transformó en el interés principal del capital, a través de mecanismos tales como: eliminación de competidores, reducción de salarios, recorte de gastos sociales, introducción de innovaciones tecnológicas, traslado de la producción a regiones con costos laborales menores. Para lograr estos objetivos en muchos países del mundo en general y en Latinoamérica en particular se acudió a la represión política contra las resistencias populares, lo que tuvo como corolario el reforzamiento de la disciplina laboral (Gunder Frank, 1982).

Más allá de las características regionales, ciertos aspectos marcan la transición entre un modelo de acumulación y otro: a) la importancia que adquirió el capital financiero, que pasó a ser el eje central de la economía; b) el reposi- 
Trabajo y SALUd EN LOS AÑOS DE LA REESTRUCTURACIÓN PRODUCtiva $\mid 83$

cionamiento de la clase trabajadora en cuanto a su importancia sobre la definición del orden social y económico; c) la implementación de importantes cambios en la organización industrial tendientes a la flexibilización del proceso productivo y la utilización de la fuerza de trabajo, entre los que se desatacaron la extensión de la subcontratación y tercerización de partes del proceso productivo antes pertenecientes al núcleo (Sayer, 1997).

Menéndez resalta que estas transformaciones, desde el punto de vista de la salud de los trabajadores, generaron un aumento de la morbilidad relacionada con las condiciones de trabajo, a partir de la incorporación de materiales y sustancias tóxicas, el aumento de los ritmos de producción, el aumento de la desocupación, la anulación de condiciones mínimas de seguridad social, entre otros. Asimismo, resalta el aumento tendencial de las enfermedades mentales, a las cuales se asocia por ejemplo el alcoholismo (Menéndez, 1986).

El caso argentino, si bien comparte con el proceso global dos características fundamentales: la depresión económica y la concentración del ingreso, tiene aspectos particulares fundamentales para la comprensión histórica de las últimas décadas. Como plantea Basualdo:

La reestructuración económica y social no respondió a una adscripción ideológica a las reformas que se llevaba a cabo en la economía mundial, ni tampoco un proceso digitado exclusivamente por las fracciones del capital extranjero a través de sus representantes políticos que eran los organismos internaciones de crédito. Su peculiaridad no radicó únicamente en su imposición a sangre y fuego por parte de la dictadura militar sino que también se trató de una 'revancha clasista' sin precedentes contra los sectores populares. (Basualdo, 2011, p. 17)
Esa revancha implicó la interrupción del modelo de industrialización por sustitución de importaciones (ISI), como manera de quebrantar las bases estructurales que posibilitaban la fuerte organización y movilización popular.

Este nuevo régimen de acumulación, impactó de manera brutal sobre las condiciones de vida de la clase trabajadora. Como consecuencia directa de las políticas económicas, baste mencionar que en los primeros ańos del gobierno militar cerraron más de 12.000 establecimientos industriales y cayó en 10 puntos la producción industrial. En términos económico-políticos, este régimen socavó las bases del poder de las organizaciones de trabajadores, a través de la detención, tortura, desaparición y/o asesinato o exilio forzoso principalmente, aunque no exclusivamente, de los activistas. Asimismo, prohibió la actividad sindical, anulando - entre otros derechos laborales - el derecho a huelga e intervino la mayoría de los grandes gremios. La efectividad de tal política represiva se explica asimismo por la complicidad y en muchos casos co-actuación en hechos represivos, de civiles como es el caso de ciertas empresas que pusieron a disposición la infraestructura edilicia y logística para la represión de los trabajadores (Basualdo, 2006; Basualdo, Barragán \& Rodrígues, 2010). La conjunción de todas estas medidas tuvo como consecuencia la caída abrupta del salario real, que disminuyó en términos generales en un $40 \%$ respecto de los vigentes en 1974. La caída de la participación de los asalariados en la distribución del ingreso nacional fue un hecho fundacional de la dictadura militar, que se redujo del $43 \%$ en 1975 , al $25 \%$ en el momento de menor participación en el año 1977, disminuyendo aún más durante crisis hiperinflacionaria de 1982 a $22 \%$ (Basualdo, 2010).

A partir de 1983, recuperada la democracia en el país, el gobierno de Raúl Alfonsín - luego 
de una primera etapa económica truncada que intentó revertir algunos de los legados regresivos - dio continuidad a los lineamientos de la dictadura (Azpiazu \& Schorr, 2010). Asimismo, durante esta década, comenzó un proceso de incorporación de tecnología en grandes empresas siderúrgicas, que determinó que entre fines del 80 y principios del 90, las empresas encararan importantes reestructuraciones en la organización del trabajo (Bisang, 1989; Jabazz, 1994). Durante la "larga década del '90" - período que va desde 1989 hasta el $2001^{4}$-, los gobiernos constitucionales de Carlos Saúl Menem y Fernando De la Rúa profundizaron en términos de política económica el proceso de desindustrialización y valorización financiera (Azpiazu \& Schorr, 2010; Basualdo, 2010; Nochteff, 1999). Siguiendo las recomendaciones del llamado Consenso de Washington se implementó la apertura económica asimétrica, desregulación y privatización de empresas públicas. En términos políticos, se profundizó la fragmentación de la clase trabajadora principalmente a partir de la flexibilización laboral, el aumento de los índices de desocupación, subocupación y sobreocupación (Novick, 2000; Santarcángelo \& Schorr, 2000).

En el caso de la industria siderúrgica, esas reformas implicaron la privatización del complejo siderúrgico estatal y diversas medidas desregulatorias que hicieron que entre 1989 y 1993 se consolidara una fuerte estructura duopólica entre los grupos económicos Techint y Acindar (Azpiazu, Basualdo \& Kulfas, 2007). Esta situación macroestructural unida a fuertes procesos de reorganización del trabajo, tendió al desmejoramiento de las condiciones de trabajo de grandes sectores de la población. Se profundizó la flexibilización de los procesos productivos y de las modalidades de contratación extendiéndose el fenómeno de tercerización (Bisio, Korinfeld \& Neffa, 1999), disminución de costos impositivos directos e indirectos a favor de las patronales, descentralización de las negociaciones colectivas, privatización de los servicios de seguridad social y salud de los trabajadores, a la vez que se ligaron los aumentos salariales a los aumentos de la productividad ${ }^{5}$.

Todas estas transformaciones tuvieron fuertes impactos sobre la clase trabajadora, que vio afectadas desfavorablemente las bases económicas y políticas que posibilitaban una gran potencialidad de organización sindical.

En el caso de la ex Propulsora Siderúrgica, el proceso de reestructuración productiva comenzó aproximadamente en el año 1988 y culminó en 1993. Durante ese período, no sólo hubo una reorganización importante de la producción en las líneas productivas a partir de la implementación de nuevas formas de organización del trabajo, sino que además se cerraron y posteriormente tercerizaron la mayoría de los sectores de servicios. Estas transformaciones implicaron la aplicación extendida de retiros voluntarios.

Remitiéndonos al proceso histórico de más largo plazo, hemos identificado dos momentos claves de quiebre de la organización sindical: el proceso iniciado a partir de la dictadura militar, donde se operó el primer desmembramiento del cuerpo de delegados a través de mecanismos represivos que incluyeron la desaparición de aproximadamente 13 delegados y, un segundo momento entre los años 1990 y 1993, donde en un proceso de pérdida paulatina del poder de los trabajadores se operó la desafiliación sindical de la mayoría de los delegados (Esponda, 2008).

\section{Los cuerpos para el trabajo}

Como dijimos en la introducción, retomamos las elaboraciones de Scheper-Hughes \& Lock (1987) para pensar las dimensiones a 
Trabajo y SALUd EN LOS AÑOS DE LA REESTRUCTURACIÓN PRODUCTIVA $\mid 85$

partir de las cuales la vida de los trabajadores se vio condicionada, afectada y modificada en los distintos momentos históricos. La diferenciación y a la vez la relación entre los tres cuerpos - que realizan las autoras - nos permite visualizar cómo las grandes transformaciones estructurales afectan a las poblaciones modificando y condicionando su cotidianeidad.

La reflexión sobre relación entre los tres cuerpos, tiene el objetivo de superar el dualismo cartesiano, que encuentra en los binomios cuerpo/ mente, psicológico/somático, real/irreal, racional/irracional, las formas de explicación de gran cantidad de las problemáticas sociales complejas.

Muy sintéticamente, el nivel del cuerpo individual, remite a la experiencia a partir del propio cuerpo y sus partes, la vivencia fenoménica de salud o enfermedad, dolor, etc., a partir de la cual ha trabajado la medicina occidental. El segundo nivel, el cuerpo social, incorpora al cuerpo y sus productos, como vehículo en la elaboración de mapas cognitivos para representar el orden natural, sobrenatural y social. En este sentido han trabajado antropólogas y antropólogos como Mary Douglas (1973) y Needham (1963), que han podido desentrañar a partir del análisis de metáforas y rituales, cómo ciertas nociones están asociadas y sirven a la comprensión de la estructura social. En el sistema capitalista, el cuerpo social, es transformado en mercancía que como fuerza de trabajo - asiste al engranaje productivo, actualizando la vieja división dicotómica entre cuerpo/trabajo manual y mente/ trabajo intelectual. En ese momento histórico toman forma las metáforas cuerpo-máquina, donde incluso el tiempo individual y social del sujeto es particionado en función de las necesidades productivas. Este nivel tiene la virtud de poner en relación el sufrimiento y el padecimiento cotidiano del cuerpo individual con las tensiones y contradicciones del orden social. Finalmente, el nivel analítico del cuerpo político se vuelve imperioso para comprender la reproducción del orden social y político. Cuando el sentido del orden social se ve amenazado por algún motivo, se intensifica el control social con el fin de someter el cuerpo individual y el cuerpo social al cuerpo politico. Es en este nivel donde podemos ver que los límites entre el cuerpo social y el individual se vuelven borrosos.

Para lograr la conformación de estos cuerpos necesarios para el mantenimiento del orden social, se ha recurrido a métodos de mayor o menor dramatismo. El uso de la tortura física por los estados modernos, por ejemplo, resulta la más gráfica ilustración de la subordinación del cuerpo individual al cuerpo politico, con el objetivo de afirmar cada vez más el control sobre la población, como una "realidad incontrastable" (Scheper-Hughes \& Lock, 1987, p. 26).

$\mathrm{Si}$ analizamos nuestra historia reciente desde esta perspectiva, podemos encontrar claramente diferentes momentos y grados de dramatismo en el ejercicio del control social para lograr la subordinación del cuerpo individual al político. La dictadura fue claramente el punto más gráfico y de mayor dramatismo. Sin embargo, todo el período que abarca el régimen de desindustrialización y valorización financiera, con sus diversos mecanismos, profundizaron el camino de tal sometimiento. La desocupación, la subocupación y la precarización de la población ocupada, junto al aumento dramático de los índices de pobreza e indigencia, a nuestro entender ejemplifican los hechos que denominaba Foucault como biopolitica, ya que apuntan a una regulación de la población, que efectuada en múltiples dimensiones, afecta de manera muy clara la vida cotidiana de grandes poblaciones y sus condiciones de salud y reproducción ${ }^{6}$.

En las páginas que siguen profundizamos cómo estas grandes problemáticas se ven expresadas en las narrativas de los trabajadores. Los materiales de campo sobre los que trabajamos se 
componen de entrevistas, conversaciones y observaciones realizadas por la autora en diferentes etapas a partir del año 2005, con distintos trabajadores y ex trabajadores de Siderar, Planta Ensenada, pertenecientes a distintos sectores productivos, con distintas jerarquías (supervisores, jefes de sección, operarios), activistas y no activistas sindicales; y con trabajadores retirados y luego subcontratados por la empresa como tercerizados. Asimismo, citamos fragmentos de un escrito inédito de un ex trabajador ${ }^{7}$.

\section{El trabajo bueno para pensar}

La Madre Línea: El sudor vaporoso y las ondulaciones de las entrañas, los cabellos revueltos de refil; el chirrido de dientes como si mordiesen una brida; el jadeo ininterrumpido y monótono; el alarido estrepitoso de un violento tirón, o la convulsión de una pliega, evidencian el trabajo de parto de la línea. Todo está dispuesto en la sección maternidad [...] El refilador, jefe médico; operador del banquito, instrumentista; ayudante evacuador, enfermero; zunchador, mucamo, están atentos al grito metálico de vida. La perfección programada del proceso productivo emula la naturaleza: iiZas!! El anuncio de que la máquina tuvo descendencia... [...] Y aún a pesar de la rutina del oficio o la indiferencia, el universo cambia el ritmo millonésimo de segundo. Radares de ternura lo detectan. Bulones, tuercas, arandelas juntas, células y átomos de intimidad de personas y cosas, se estremecen y aplauden el milagro del nacimiento. [...]

Avanza el ruido, con la g, con la r, con la k, con el alfabeto entero del lenguaje motor. Y la chapa, serpiente acerada, avanza frotando sus costillares y resopla sumergiéndose. El pescador progresa, recoge el reel de su avaricia. Mentes vacías y oídos rotos, los pescados, dan movimiento conti- nuo a la locura (Fragmentos extraídos de libro inédito de Ángel Molinero, ex trabajador de Propulsora Siderúrgica, zunchador).

El trabajo no sólo es construido como una actividad ambivalente, sino que las múltiples metáforas que hacen alusión al proceso de trabajo, encuentran en él un recurso útil para hablar de las categorías básicas de la vida cotidiana: la madre ${ }^{8}$, el nacimiento, la reproducción, el envejecimiento y la muerte. El trabajo encarnado en el cuerpo de los obreros, nos permite situar su vida, su rutina, en ese sistema que los implica superándolos como individuos que desarrollan funciones parciales para completar la totalidad.

La ambivalencia se expresa en que por un lado los incluye, les permite crear, sentir, asistir como hombres al nacimiento, sentirse extasiados por esa gran maternidad, que además los identifica socialmente y les da un lugar importante en el orden social. Por el otro lado, la rutina los anula, los encierra, los reduce a engranajes de la gran maquinaria cercana a la locura y la muerte. Castro señalaba esta misma ambivalencia en su estudio de los habitantes de Ocuituco (México), quienes percibían que las condiciones de trabajo los desgastaba, los acababa, y eventualmente contribuía a la muerte; a la vez que en otras ocasiones estas mismas condiciones eran consideradas como la razón de tener una buena salud al desarrollar resistencia física (Castro, 2009).

Como plantea Mary Douglas (1973) para ciertos ritos, esta poética sobre el trabajo tiene la capacidad de incorporar la idea de que la muerte y el sufrimiento, no sólo forman parte integrante de la naturaleza sino también del orden social, expresan relaciones sociales y configuran jerarquías y asimetrías. En ese sentido, esa maternidad poderosa con capacidad de afectar positiva o negativamente a los trabajadores, nos está hablando de las asimetrías 
TRABAjO Y SALUd EN LOS AÑOS DE LA REESTRUCTURACIÓN PRODUCTIVA $\mid 87$

diarias que subordinan a los obreros no sólo en el espacio fabril, sino dentro del sistema social más amplio. Por otro lado, si bien por momentos el trabajo fue valorado negativamente, por su intermedio el sujeto se constituye y valoriza?

La fábrica fue construida en dos sentidos diferentes. Por un lado, como un espacio de vida, donde - en los intersticios de la actividad productiva y a escondidas - se realizaban innumerables actividades tales como comer, dormir, leer el diario, hacer un asado, darle de comer a las palomas, tomar sol, vender mercaderías, fabricar artesanías. Por otro lado, también fue sinónimo de hastío, cansancio, encierro, envejecimiento expresado en frases como "la fábrica nos quitó la juventud", "nos armó un círculo cerrado", "nos embruteciô":

Conozco muchachos que no pueden ni venir en el colectivo, no pueden ni llegar a la fábrica por el fastidio que les genera. Entonces toman la jubilación anticipada, y piensan que su vida va a ser leer el diario y hacer las compras, ir a calle 8 (calle comercial de la ciudad vecina de La Plata)... y después se vuelven locos en la casa, están llorando en la puerta de la fábrica. Ellos no se daban cuenta de que acá la cabeza te trabaja muy rápido, es como una máquina que trabaja y trabaja y la parás de golpe... se atrofian (Franco, trabajador de Siderar, perteneciente al staff). ${ }^{10}$

A pesar del rechazo y el hastío relacionado con ir a trabajar, la posibilidad de "dejar" la fábrica, de tomar jubilaciones anticipadas o retiros voluntarios en los primeros años de los 90, fue planteada como posibilidad de "atrofia”. Incluso más, en ańos recientes, otro trabajador expresaba que en la fábrica "los muchachos están preocupados por la muerte de muchos compañeros recién jubilados... entonces no se quieren jubilar viste?" (Carlos, jubilado de Siderar, operario de planta $)^{11}$. La muerte física, está planteada como consecuencia de dejar el trabajo, actualizando la noción de la fábrica como espacio dador de vida.

En su dimensión individual, estas construcciones podrían entenderse como recursos para describir los orígenes de un sufrimiento o dolencia e imaginar posibles soluciones, como proceso primario para contener la disolución y posibilitar la reconstitución del mundo a partir de introducir los sucesos por los que transita el sujeto en una historia o trama significativa. Es decir, podríamos pensar esta narrativa sobre la muerte y la necesidad de permanecer en la fábrica en su doble aspecto: como localización del origen de la muerte ${ }^{12}$ y a la vez encuentro de una posible solución, que está inmersa en la historia del sujeto trabajador. Si como plantea Good (1994), la enfermedad no ocurre en el cuerpo si no en la vida, en un tiempo, en un lugar, en una historia, el permanecer en la fábrica y tal vez morir en ella, evita esa disolución imaginada por el obrero al momento de su jubilación.

Esta trama significativa profundiza e instituye el sentido de la vida del sujeto en tanto trabajador, identificándolo con un yo saludable en contraposición a un yo no saludable, cuyo límite es la capacidad de seguir trabajando. Se refleja aquí cómo la noción de cuerpo saludable - en tanto apto y disciplinado para el trabajo -, sigue teniendo una gran efectividad (Crawford, 1994), relacionando la utilidad con la posibilidad de continuar con la actividad productiva.

Esta misma trama significativa entre salud/ enfermedad y capacidad o incapacidad laboral fue documentada por Grimberg quien planteó que "la definición de enfermedad [por parte de los trabajadores] supone como primera condición 'no poder ir a trabajar"' (1997, p. 202). Podemos rastrear en otras investigaciones, las percepciones que identifican la incapacidad laboral con la enfermedad - aún después del retiro. Guedes documentó la existencia de una relación establecida entre enfermedad e imposi- 
bilidad de trabajar o incapacidad para el trabajo en el momento de la jubilación o del retiro. Si bien puede sentirse como el momento de liberación de la subordinación al patrón, también se asocia a la enfermedad, a la inactividad. La jubilación está inserta en este entramado de significaciones que asocia jubilación-inactividad-enfermedad-incapacidad para el trabajo y vejez cuestionando la identidad del hombrel trabajador (Guedes, 1997, p. 286).

Todas estas construcciones y percepciones sobre el cuerpo y la salud, no pueden ser examinadas reduciendo el análisis a la dimensión individual, ya que el cuerpo del trabajador está anclado en el orden social y político. Como planteaba Bourdieu respecto del habitus de clase:

(...) el habitus intenta ponerse al abrigo de crisis y cuestionamientos críticos, asegurándose un medio al que está lo más adaptado posible, es decir, un universo relativamente constante de situaciones adecuadas para el refuerzo de sus disposiciones, ofreciendo el mercado más favorable a sus productos (id., 1991. p.105).

En este marco, el espacio fabril tiene la capacidad de contener a los trabajadores, más allá de los padecimientos cotidianos a los que los somete, trazando un espacio de pertenencia y definiendo márgenes en los cuales la vida del trabajador transcurre en el marco de reglas y normas conocidas, que los hace sentir más seguros y protegidos ${ }^{13}$.

\section{Resistir el trabajo}

Las percepciones sobre las condiciones de trabajo, la salud y los accidentes laborales, también están atravesadas por dimensiones políticas, sociales y económicas. La noción de "resistir" puede ser rastreada en los relatos de los trabajadores, aunque con diferentes sentidos y significados, que tensionan desde la experiencia de clase los distintos momentos histórico-políticos y económicos.

La idea de "resistir" el trabajo conduce a dos razonamientos diametralmente diferentes. Resistir, ser fuerte, aguantar en este tipo de actividades industriales suele ser un valor muy importante para el trabajador. La fortaleza ante la adversidad, ante determinadas condiciones de trabajo desfavorables para el cuerpo y la salud, la incorporación de los accidentes de trabajo como hechos que suceden y conforman los "gajes del oficio" a los que hay que estar dispuestos, constituyen una parte de esta noción de "resistir" el trabajo, soportarlo, aguantarlo".

Por otro lado, "resistir" también conduce a la necesidad de transformar ese orden instituido que en determinados momentos políticos se presentaba como inmutable, aunque reconocieran muchas de sus consecuencias perniciosas, como por ejemplo factores más "materiales" o "físico-químicos" de la producción, o aquellas referidas a la organización del trabajo y las relaciones sociales de producción.

El sistema de turnos rotativos por escuadras $^{15}$, que afecta a una gran parte de los trabajadores, genera una desvinculación con aspectos de la vida social exterior y consolida esa sensación de que "nos armaron un círculo cerrado”. Como plantea Laurell (1978, p. 4) "El poder organizativo coercitivo del trabajo, en efecto, se establece a partir del momento en que ningún obrero puede planear un 'proyecto de vida' sin tomar como punto de partida el tiempo y la energía que tienen que dedicar al trabajo". Asimismo, el turno noche específicamente genera una sensación de desajuste diario: 
Te espero hoy a las 22 hs donde siempre. La Noche. A las dos semanas justas de la última cita se renueva puntualmente el compromiso. El imperativo mensaje invierte el giro de los astros, subvierte las costumbres [...]. La mojadura del vas a llegar tarde desenreda las pestañas. A medida que la higiene despabila y pone raya a las ideas, menguan los tumbos y tropezones ante una realidad trastocada. El estómago, palpitando ansiedad, duda entre comer el desayuno o tomar la cena. Chau es la síntesis lúcida de no saber ańadir a buenas, tardes, días, o noches (Ángel Molinero, ibidem).

A su vez, este desajuste se vincula con otras consecuencias directas en el ámbito productivo:

Hay actos inexplicables de comportamiento laboral (accidentes, fallas operativas, etc.) que pueden tener su causa en la discronía, o sea, el desajuste que se produce entre los ritmos internos, o circadianos, y los externos, provocados por los turnos de trabajo rotativos (id., ibidem).

Laurell (1982, p. 21) plantea que "Las consecuencias sobre la salud derivadas del trabajo por turnos, especialmente cuando hay rotación, involucra problemas como trastornos digestivos incluyendo úlcera, accidentes más graves, agudización de problemas nerviosos, insomnio y fatiga patológica", a lo que se añade "el desgaste y envejecimiento prematuro y, como consecuencia, el acortamiento de la vida”.

Además del sistema de turnos rotativos, otros factores son reconocidos como nocivos por los trabajadores como: exposición constante a ruidos y estruendos, a fuertes olores, a sentirse "drogados" al "chupar ácido clorhídrico" y al cambio continuo entre altas y bajas temperaturas.
En los años previos a la reestructuración de los noventa, había dos sectores productivos considerados los peores para trabajar: las grúas y el pool. ${ }^{16}$

Por ahí hay gruístas que al rato quieren bajar a hablar con alguien y hay otros que se llevan el mate... y no quieren bajar más pero también por el tipo de trabajo que es, muchos han terminado enfermos de la cabeza porque si vos tenés una cosa en la cabeza y estás 8 horas dándole a eso y a eso... te volvés loco (Carlos, jubilado de Siderar, operario de planta).

Tanto las grúas como el pool fueron considerados nocivos en cuanto a las relaciones sociales, la grúa por el aislamiento y el pool por la constante rotatividad, la ausencia de espacio físico que lo convierten en algo así como un 'no' sector.

La otra es que cuando vos no tenés nada que hacer ¿adonde vas? [...] nadie te pedía que laburés, te mates... nada, pero no sabías donde meterte ¡entendés? Estás supeditado a que alguien te convide un mate o... vos no podías andar por la fábrica con el diario abajo del brazo ¿̇iste? (nos reímos) ¿entendés? En cambio si vos estás en tu sector, vos tenés tu trabajo pero vos manejás los tiempos, podés decir 'che, me escapo a leer el diario, me escapo...' Eso es lo que tiene de feo el pool (idem).

Vemos que para evaluar la salud, las condiciones de trabajo y los beneficios o perjuicios de una sección o puesto de trabajo, no sólo son tomadas en cuenta las características "materiales" de producción sino también aquellas que tienen que ver con las relaciones sociales en el trabajo: 
Porque esa es industria pesada... el tiempo de vida útil es de 15 ańos... después ya tenés problemas de oído, de hipertensión, de úlcera... por los efectos del ruido, por los efectos de la presión de la supervisión [...] porque todas las empresas de industria pesada, te caga la salud viste, te caga todo, y eso lo teníamos bien marcado [...]. Porque te jode la vista, te jode el corazón, te jode los pulmones, la tensión nerviosa también te altera, te disminuye la potencia sexual: comprobado; todos se reían, sí ja ja reíte, teníamos un informe médico que el ruido disminuye la potencia... todo, todo disminuye [...] porque en realidad nosotros peleábamos por 8 horas de trabajo y que de esas horas de trabajo reditúe un salario acorde, que no tuvieras que quedarte ahí en la fábrica con los ruidos, con un montón de presiones que afectan la salud (Ramón, ex trabajador de Propulsora Siderúrgica, gruísta, delegado de fábrica) ${ }^{17}$.

Este trabajador y principal dirigente fabril hasta su renuncia en el año 1991, introduce dos cuestiones significativas. Una de ellas es la importancia de la actividad sindical para reducir las consecuencias desfavorables del proceso de trabajo sobre la salud de los trabajadores, evitando - por ejemplo - las jornadas laborales extendidas por la realización de horas extras. Esta cuestión es muy conflictiva, ya que de la realización de horas extras depende muchas veces la posibilidad de percibir un mayor salario que permite superar la mera subsistencia material. En la mayoría de los casos, el recuerdo de la construcción de la casa propia, está asociada a la posibilidad de realizar muchas horas extras, constituyéndose en un deseo para el trabajador, como lo documentó Ribeiro (2006, p. 136-141) en su investigación sobre la construcción de Brasilia. Tan es así que en algunos casos la extensión de una medida de fuerza sindical que implicara la no realización de horas extras, era considerada como un problema para la mayoría de los trabajadores que veían disminuidos sus ingresos, llegando incluso al fracaso de la acción ${ }^{18}$.

Volviendo al testimonio anterior, allí se plantea cierta invisibilización de problemas de salud tales como la "tensión nerviosa" o la disminución de la potencia sexual ${ }^{19}$. Finalmente también incorpora la importancia de otros aspectos menos visibles que afectan la salud y que se perciben como "presiones" que perturban psíquicamente al trabajador. Estas "presiones" son nombradas negativamente por la mayoría

Era una situación enfermiza, yo conozco gente que ha quedado estúpida, los ves caminando por la calle como una baba ¿por qué?... por las presiones. Presión del trabajo, presión de los delegados, presión de los supervisores, presión de la empresa, presión del chusma... la presión de la selva, porque es la selva, del sálvese quien pueda (Martín, ex trabajador de Propulsora Siderúrgica, electricista $)^{20}$.

La "presión del chusma" - mencionada por el entrevistado - refiere a los "chismes" que constituyen un hecho muy importante en la fábrica. Los trabajadores recuerdan que en momentos de baja producción, los chismes acerca de posibles despidos, suspensiones, profundizados por las frecuentes paradas de producción “terminaban con algún infartado". Según este mismo trabajador esos chismes eran propiciados por la empresa que tenía sus propios "generadores de bolas"21 que empezaban a correr expandiéndose por toda la fábrica. En consonancia con lo anterior, el relato que sigue expresa claramente la tensión que produjeron los cambios tendientes a la flexibilización laboral a principios de los 90 . 
TRABAjO Y SALUd EN LOS AÑOS DE LA REESTRUCTURACIÓN PRODUCTIVA |9I

Porque también el otro problema... es que cuando usted entra a la fábrica siempre... "¿qué novedad hay, qué novedad hay, qué novedad hay, qué novedad hay?" como los cambios son constantes, son constantes como que la gente nunca tiene la tranquilidad de decir-bueno, me quedo a trabajar y no me va a pasar nada- $\mathrm{Y}$ siempre tiene una cierta angustia [...] no existe más el esquema de que en 20 años [...] y después tiene la otra carga que no sabe si se va a jubilar porque por ahí [...] un cambio le produce una salida de la fábrica. Todo eso genera tensiones, todo el día, todos los días, la gente se cansa de eso (Francisco, ex trabajador de Propulsora Siderúrgica, electricista, delegado de fábrica) ${ }^{22}$.

Todas estas tensiones generaron momentos de mucha angustia e incertidumbre con respecto al futuro cercano expresados en frases como “a la fábrica sabes que vas, pero no sabés si volvés” ya que diariamente se planteaban rumores de crisis empresarial, que implicarían drásticas reducciones de personal. Es interesante pensar cómo estas mismas frases se escuchaban en referencia a la dictadura militar, cuando muchos compañeros eran detenidos o desaparecidos en los lugares de trabajo o al salir de la fábrica. Es decir, el mismo efecto de disciplinamiento a través del temor, fue aplicado en distintos momentos históricos, aunque en distintos niveles: en un caso se perdía la vida y en el otro el trabajo.

Con respecto a los padecimientos de los trabajadores en la fábrica, si bien el proceso de medicalización opera designando como enfermedad a un número cada vez mayor de situaciones sociales (Freidson, 1978, p. 248-253), es interesante pensar como en este caso, ciertas situaciones que tienden a ser consideradas como enfermedades en la actualidad, como la drogadicción o el alcoholismo, fueron consideradas como desviaciones por la patronal y reprimidas, al menos en los casos en que los trabajadores eran descubiertos consumiendo. Sin embargo, no se registraron políticas empresariales integrales al respecto, así como tampoco respecto de problemas de salud mental o situaciones familiares críticas que son considerados por los trabajadores como consecuencia de las políticas de reestructuración productiva tales como divorcios, depresiones y suicidios ${ }^{23}$.

Muchos de los trabajadores que continúan trabajando para Siderar - pero como tercerizados - si bien recuerdan que en Propulsora se trabajaba bajo "más presión" los cual les generaba diversos problemas de salud, reconocen que en la actualidad no están exentos de problemas similares, agravados porque en esta nueva condición vieron reducir sus salarios aproximadamente a la mitad.

Entre sus padecimientos actuales más comunes reconocen: hipertensión, cardiopatías, accidentes cerebro vasculares, cáncer, diabetes, colesterol, problemas estomacales como "acidez", episodios aislados de infecciones en los pies por el uso de botines, hepatitis, entre otros; que separan de aquellos relacionados con factores de índole psicológica como depresiones, ataques de pánico, ansiedad, "mal humor", taquicardia por nervios o discusiones en el lugar de trabajo e insomnio. Muchos de estos padecimientos actuales, como los asociados a la salud mental, cáncer, problemas gastrointestinales entre otros, se hicieron más frecuentes a partir del proceso de reconversión industrial (Sánchez \& Yanes, 1995).

De la mano con la negación de la responsabilidad por parte de la patronal respecto de las situaciones antes nombradas, es importante remarcar que si bien el proceso de expansión de la medicina ubica dentro de su jurisdicción un rango cada vez más grande de "problemas personales o conductas desviadas" (Conrad \& Schneider, 1985, p. 16), genera a la vez una redefinición del campo, donde las consecuencias 
concretas de modelos económico-políticos sobre la salud de la población, son concebidas únicamente como problemas pertenecientes al ámbito de lo individual y lo privado. Se refuerzan de esta manera las soluciones médicas individualizantes, que si bien son sumamente necesarias, al no ser complementadas con otro tipo de intervenciones, colaboran concretamente con la negación de la relación entre esos problemas de salud, el orden social y su reproducción.

A partir de la selección de dos materiales de campo vamos a explorar brevemente algunas nociones respecto de los accidentes de trabajo, donde encontramos la existencia de dos visiones principales respecto de la significación de los accidentes. Aquellas que explican los accidentes por una asociación entre malas condiciones ambientales de trabajo, priorización de las necesidades de producción frente a la seguridad y bajas posibilidades de organización sindical; y aquellas que incorporan los accidentes como hechos "normales" que suceden en toda fábrica y que forman parte del oficio.

Uno de los accidentes relatados ocurrió hacia finales de la dictadura, en el año 82. En este período muchos de los derechos laborales obtenidos en luchas previas habían sido anulados "con el argumento de que había sido producto de presiones de la guerrilla, de los subversivos... todo eso". En este contexto, ocurrió un accidente fatal en la planta, relatado de esta manera por Ángel Molinero:

Él y los demás muchachos estaban laburando en la sección decapado, a unos 20 metros de altura, apoyados en tres o cuatro tablones [...] sin barandas, cinturón de seguridad ni nada que pudiese protegerlos del mínimo descuido. Bajo sus pies, en vez de una red que los embolsara si caían, un plástico negro para no manchar de pintura las bobinas y ocultar a sus ojos la trampa mortal del vacío. Además, el puente grúa en continuo ir y venir deteniéndose a 10 metros de ellos [...] con su mole impresionante y avasalladora, y el rugido poderoso del desplazamiento, ponían el corazón en un puño haciendo temblar las piernas. Ya se sabe... seguridad termina donde empieza producción. El día 9 hizo 28․ Junto a las chapas, respirando pintura y ácido clorhídrico, con las máquinas funcionando y las piletas calientes, teniendo en cuenta que el calor se almacena en las alturas ¿en qué condiciones ambientales trabajaban? si a esto añadimos las 12 o 14 horas de jornada, al palo cien por hora, que son contratados, sin seguro, obra social ni afiliación sindical, completamos el revelado de la cruel explotación (id., ibidem).

Este tipo de explicación, que pone el énfasis en la responsabilidad empresarial difiere de otras explicaciones que tienden a naturalizar que el cuerpo del trabajador esté puesto a disposición del patrón o de la actividad productiva, al igual que su fuerza de trabajo

Cuando se me terminó el mandato (como delegado sindical) en el año 92 volví a trabajar con la frente alta, tampoco me llené de plata porque lo que tengo, lo tengo gracias a que perdí la mano (en un accidente de trabajo en el año 1997) (Joaquín, trabajador, inspector de calidad, fue delegado de UOM - Unión Obrera Metalúrgica) ${ }^{24}$.

El cuerpo y ciertas pérdidas - como la pérdida habitual de dedos de la mano - resulta de un movimiento inverso de desvalorización/ valorización. Desvalorización del cuerpo en sentido orgánico; y valorización en un sentido estrictamente económico-material, donde el accidente es incorporado en una trama que relaciona "lo que tiene" materialmente con la mano que perdió en un accidente de trabajo, 
donde su cuerpo es percibido - en definitiva - como una mercancía. En este sentido, podemos pensar este movimiento como otra forma en que se expresa el sometimiento del cuerpo individual al cuerpo político.

Por otro lado, esta aceptación del accidente como algo habitual, expresa una relación más compleja que refiere a la modalidad en que el sujeto está inserto en el mundo en tanto miembro de una cultura o clase, donde el trabajo y sus consecuencias están incorporados en el cuerpo en tanto prolongaciones del propio ser, sin que estas sean, como planteó Merleau-Ponty, equiparadas con una forma de conocimiento (apud Alves \& Rabelo, 2003). Esta inserción en el mundo, más allá de las diferentes formas en que sea construida por los sujetos, debe analizarse a partir de las prácticas sociales, atravesadas por disputas entre fuerzas sociales inmersas en relaciones de hegemonía y subalternidad (Menéndez, 2001).

\section{Reflexiones finales}

En este artículo exploramos cómo las construcciones de los trabajadores de una gran fábrica metalúrgica sobre su cuerpo, salud y enfermedad están imbricadas en procesos histórico-culturales y económicos específicos, en relaciones que incluyen no sólo a los trabajadores y patrones, sino también fuertemente al Estado y sus políticas.

Retomando a Foucault (1991), estado y empresa, se erigieron como los nuevos soberanos que detentan el derecho sobre la vida en distintos momentos históricos y con distintas modalidades. En la historia reciente argentina, podemos pensar que ha habido una conjunción de modalidades. En una primera etapa, operó el poder de muerte instrumentalizado con el genocidio por la última dictadura militar, en com- plicidad con patronales de los grandes grupos económicos. Posteriormente, operó el poder cuya más alta función no es matar sino administrar la vida, que en la década del noventa se materializó a través de gobiernos constitucionales, fundamentalmente con la promulgación leyes y reglamentaciones que redujeron drásticamente los derechos de trabajadores y trabajadoras.

Otro núcleo importante que mediatiza las construcciones de los trabajadores es la experiencia de clase que lejos de ser unívoca, asume variados sentidos y significados que condicionan la percepción sobre sus padecimientos. Estos sentidos combinan toda una serie de experiencias de valoración positiva del trabajo como espacio vital, creativo, constitutivo de la identidad individual y colectiva; con la conciencia sobre la explotación y los problemas de salud que esta genera.

Las relaciones que se establecen con el trabajo están marcadas por contradicciones y ambivalencias que remiten a las características de la relación capital-trabajo donde la fuerza de trabajo y el cuerpo útil del obrero se valoriza como mercancía. Las posibilidades de resistencia y organización sindical para lograr mejores condiciones de trabajo, lo cual se asocia directamente a la salud, no sólo están condicionadas por esas contradicciones y el momento histórico particular, sino también por los habitus que expresan tensiones entre la tendencia a la reproducción y la tendencia al cambio. Esta última, sólo podría profundizarse a través de la acción colectiva.

El proceso de desindustrialización y valorización financiera, que en el marco de la hegemonía neoliberal a nivel global, atravesó la Argentina desde 1976, sentó las bases estructurales para operar un quiebre en las modalidades de acción colectiva previas, reforzando la tendencia hacia la aceptación de las condiciones de trabajo impuestas y la necesidad de conservación del orden establecido. En este contexto, la recreación de modalidades organización 
sindical con fuerte anclaje en los lugares de trabajo, resulta fundamental para revertir esos procesos tan perjudiciales para grandes poblaciones de trabajadores y trabajadoras.

Trabalho e saúde nos anos da reestruturação produtiva. 0 caso dos trabalhadores da ex Propulsora Siderúrgica, Ensenada, Buenos Aires

resumo Neste artigo analisamos as construçôes dos trabalhadores sobre seu corpo, saúde, doenças e acidentes de trabalho em relação ao trabalho, o lugar e as condiçóes de trabalho em uma grande companhia siderúrgica no contexto da reestruturação produtiva. Nós analisaremos como estas construçóes estão atravessadas por duas questôes principais, ambas marcadas por contradições e ambivalências: por um lado, o trabalho enquanto atividade vital e constitutiva do sujeito, que compromete sua corporeidade e o valoriza como trabalhador. Por outro lado, o trabalho enquanto relação política entre trabalhadores, delegados sindicais, patróes e sindicato que expressa lutas de poder no lugar de trabalho. Os dois tópicos problematizam o modo em que os trabalhadores concebem sua própria saúde e seu corpo, o que é compreensível se o considerarmos como experiência histórica, político-econômica, ideológica e cultural ampla.

palavras-chave Trabalhadores. Reestruturação produtiva. Indústria de aço. Corpo. Saúde.

Work and health in the years of the productive restructuring. The case of the workers of the Ex-Propulsora Siderúrgica, Ensenada, Buenos Aires

abstract In this article we analyze the constructions of the workers in respect of their body, health, diseases and work accidents in relation with work, and workplace and conditions at a big metallurgical enterprise during the productive restructuring. We are going to analyze how they are related by two principal questions, both marked by contradictions and ambivalences: on one hand, we have what concerns work as a vital and constitutive activity of the subject. Here the subject's corporeity is both compromised and valued as a worker. On the other hand, we find work as political relations among workers, shop stewards, bosses and union leaders, that expresses fights over power at the workplace. Both issues problematize the way in which the workers conceive their own health and body, which is understandable if we consider it to be a wide historical, economic - political, ideological and cultural experience.

keywords Workers. Productive restructuring. Siderurgy. Body. Health.

\section{Notas}

1. Versiones preliminares de este trabajo fueron presentadas, en primera instancia, como trabajo final del seminario de Antropología Médica "Procesos de Medicalización y cuerpo", dictado por la Dra. Mabel Grimberg en el Programa de Postgrado en Antropología Social de la Universidad Nacional de Misiones. Posteriormente, una revisión del mismo fue presentado como ponencia en la IX Reunión de Antropología del Mercosur, en el GT 63.

2. El Grupo Techint es uno de los grupos económicos locales más importantes, inserto trasnacionalmente en diversas actividades económicas. La empresa que tomamos como caso se estudio (ex Propulsora Siderúrgica) fue renombrada como Siderar - Planta Ensenada - con la privatización de SOMISA (siderúrgica estatal) en el año 1993. Puede aparecer nombrada de ambas maneras en el texto.

3. Las formas en que fue expresado y experimentado el proceso de reestructuración productiva en la fábrica, nos condujo desde el inicio de la investigación a concebirla como una experiencia histórica. La mayoría de los obreros había comenzado a trabajar desde la apertura 
de la planta en 1969, y las formas que había adquirido la reestructuración en los 90, conducía necesariamente a revisar las disputas y luchas históricas, donde la última dictadura militar y los momentos previos de marcada actividad política fabril, tenían un lugar fundamental para comprender el proceso. En este sentido recurrimos a los conceptos de autores como Thompson y Bourdieu para comprender la clase, sus posiciones y disposiciones como un proceso en formación continua, donde interfieren no sólo determinantes estructurales sino también históricos, sociales y culturales (Bourdieu, 2000; Thompson, 1989a y 1989b; Meiksins Wood, 1984).

4. Esta década se considera finalizada en el año 2001 con la caída del régimen de convertibilidad que establecía un tipo de cambio fijo entre el peso y el dólar, destinado a estabilizar el nivel de precios.

5. Asa Cristina Laurell quien realizó un estudio sobre los trabajadores siderúrgicos mexicanos y cómo fue afectada negativamente su salud a partir de la reestructuración, plantea: "En Chile y Argentina se dieron procesos semejantes y aun más agudos debido a la aplicación de politicas económicas, bautizadas de shock por la escuela de Chicago, iniciadas en los años 1975 y 1976 respectivamente, que tuvieron como requisito politico previo los golpes militares y el ejercicio de una profunda represión contra el movimiento obrero" (1982, p. 24)

6. Planteaba Foucault: "[...] ese poder de muerte $-y$ esto quizá sea lo que le da una parte de su fuerza y del cinismo con que ha llevado tan lejos sus propios limites - parece ahora como el complemento de un poder que se ejerce positivamente sobre la vida, que procura administrarla, aumentarla, multiplicarla, ejercer sobre ella controles precisos y regulaciones generales" (1991, p. 165-169).

7. El trabajo de campo se realizó en dos etapas espaciadas temporalmente. La primera, entre los años 2005 y 2007. La segunda etapa, entre septiembre de 2010 y fines de 2011. Entre ambas etapas hemos realizado aproximadamente 40 entrevistas en profundidad y observaciones en un taller metalúrgico que provee servicios a Siderar. Los nombres de los entrevistados han sido cambiados.

8. Durante distintos momentos históricos, los obreros aluden a la empresa a través de la imagen de "mamá Propulsora”, que es simultáneamente "la mamá que te protege, te cobija" y la mamá "mala" "que te pega una patada” (Esponda, 2011).

9. Fernández Álvarez plantea que en los procesos de recuperación de fábricas, esta valoración positiva del trabajo se expresa en la elección de los trabajadores de erigirse como sujetos productivos, con capacidad y voluntad de trabajo, construyendo desde ahí el lenguaje de la protesta (Fernández Álvarez, 2010).

10. En el momento de ser entrevistado pertenecía al staff. Sin embargo, previamente, había sido un trabajador de planta, se había retirado y luego había sido recontratado por Siderar. Entrevista realizada el 14/09/2006.

11. Trabajador jubilado de SIDERAR, más de 30 años de servicio, fue delegado de fábrica. Cumplió diversas funciones en las líneas productivas. Entrevista realizada el 26/02/09.

12. Esta localización de la enfermedad del sujeto está en estrecha relación con la importancia que remarca Lock de visualizar al cuerpo enfermo como participante de un orden social, lo que conduce a revelar las relación íntima entre enfermedad y política (1993, p. 144).

13. El fracaso económico de muchos de los trabajadores que tomaron los retiros voluntarios en los años 90 y emprendieron actividades productivas de manera independiente fue explicado en frases como "no estábamos preparados para salir [de la fábrica]".

14. Ribeiro (2006) profundiza esta noción de "aguantar" hasta que se "revienta" en los obreros de la construcción de grandes obras civiles, asociada principalmente a la extensión de la jornada de trabajo.

15. En este sistema cada trabajador pertenece a un sector y a una escuadra. Su escuadra va rotando semanalmente entre turno mañana, tarde y noche.

16. Según los testimonios, con la reestructuración de los noventa el sector pool fue desarticulado. El pool era un sector en el que los trabajadores no tenían función específica, pudiendo ser enviados a cubrir diferentes puestos en función de las necesidades de producción.

17. Ramón, ex trabajador, ingresó en 1969 y se renunció en 1991. Fue delegado fabril e integrante de la Comisión Interna. Entrevista realizada el 13/09/05.

18. En cuanto a la relación entre realización de horas extras y militancia sindical, Florencia Rodríguez (2011, p. 16) reflexiona a partir de un documento sindical cómo las jornadas de trabajo extendidas de 14 a 16 horas influyen negativamente sobre la posibilidad de acción colectiva: "(...) el quite de horas extras tuvo sobre los trabajadores un doble efecto: puso de manifiesto el verdadero alcance de los salarios (...) y, al mismo tiempo, como reconocieron algunos compañeros 'Por primera vez, tuvimos tiempo de pensar y discutir entre nosotros. Las horas extras aunque eran nuestra única manera de subsistir prácticamente nos tenian embotados". Fragmento citado de la Revista Evita Montonera, n. 1, año 1, diciembre 1974. 
19. Este problema aflora como uno de los problemas más difíciles de tratar ya que “todos se reían”, lo cual puede estar relacionado con que atenta directamente contra las nociones de virilidad y masculinidad, asociadas a ese tipo de actividad laboral.

20. Martín, ex trabajador, ingresó en 1979 y ser retiró en 1991. Conformó una empresa con otros compañeros para brindar servicios a Propulsora Siderúrgica hasta su cierre a principios del 2000. Entrevista realizada el 23/11/2006.

21. Se refiere a las "bolas" (dichos, rumores) que empiezan a correr y se agrandan, recurriendo a la imagen de una bola de nieve. Con respecto a la importancia de los "chismes" ("fofoca") para nutrir el análisis antropológico ver Claudia Fonseca (2000). Asimismo, para entender la importancia de los rumores en un contexto institucional en el que prima la deliberada desinformación e incertidumbre, ver Emilio de Ipola (2005).

22. Francisco, ex trabajador, ingresó en 1979 y fue despedido en 1993 por su militancia sindical como delegado e integrante de la Comisión Interna. Entrevista realizada el 07/12/2006.

23. Varios de los trabajadores entrevistados reconocieron problemas de este tipo en los años posteriores a la restructuración o al retiro de la fábrica, principalmente por situaciones de privación económica o desempleo. Como ha documentado Sergio Leite Lopes (2011, p. 234) son variadas las fuentes que los obreros encuentran asociadas a la enfermedad y la propia muerte. Las condiciones de trabajo y las largas jornadas de trabajo son ciertamente importantes, pero el propio "pensamiento", la amargura de no comprender por qué el salario no alcanza. Citamos un extracto de una entrevista muy representativa en la que el obrero hablaba de la necesidad de tomar leche como manera de cortar el efecto de estar sometidos a ciertas tintas durante toda la jornada: "Pero cooperativas no les dan leche, entonces tienen que tomar un aguardiente, ¿no? $Y$ acá todos toman; hay que tomar mucho porque, si no tomás, pensás mucho en la vida [rie]. Te quedás pensando en cosas que no tienen arreglo, terminás haciendo boludeces, ¿no? [rie]. El compañero puede hasta enloquecer, ¿no?, perder el juicio. Se puede calentar por cualquier boludez. Y acá lo vemos mucho, que el compañero no se vuelve loco pero lo que vemos es que está bien triste, se queda mal, resentido... para adentro."

Una expresión encontrada frecuentemente en nuestro material de campo para denominar este tipo de estado es hacerse "mala sangre", lo cual aseguran que ha llevado a la muerte a algunos compañeros, o a ellos mismos a padecer enfermedades como hipertensión y diabetes.
24. Joaquín, trabajador de SIDERAR al momento de ser entrevistado, ingresó en 1969, fue integrante de UOM con licencia gremial durante algunos años, entrevista realizada el 24/05/2007.

\section{Referências bibliográficas}

ALVES, Natália Cristina. Corpos entre Saúde e Trabalho: A construção sociopolítica da LER como doença. Dissertação de Mestrado - Faculdade de Filosofia e Ciências Humanas, Universidade Federal de Minas Gerais, 2004.

ALVES, Paulo César \& RABELO Miriam Cristina. Medicina Tradicional. Uma reflexao a partir dos conceitos de experiencia e corpo. In: CÁCERES, C.; CUETO, M.; RAMOS, M. \& VALLENAS, S. (orgs.). La salud como derecho ciudadano: perspectivas y propuestas desde América Latina. Lima: International forum for social sciences and health / Universidad peruana Cayetano Heredia, 2003.

ANTUNES, Ricardo. Los sentidos del trabajo. Buenos Aires: Ed. Herramienta / Taller de Estudios Laborales, 2005.

AZPIAZU, Daniel; BASUALDO, Eduardo \& KULFAS, Matías. La industria Siderúrgica en Argentina y Brasil durante las últimas décadas. Buenos Aires: Ed. CEFS, FETIA y CTA, 2007.

AZPIAZU, Daniel \& SCHORR, Martín. Hecho en Argentina - Industria y economía, 1976-2007. Buenos Aires: Siglo Veintiuno Editores, 2010.

BASUALDO, Eduardo. Sistema político y modelo de acumulación: tres ensayos sobre la Argentina actual. Buenos Aires: Atuel, 2011.

. Estudios de Historia Económica Argentina - Desde mediados del siglo XX a la actualidad. Buenos Aires: Siglo Veintiuno Editores, 2010.

BASUADO, Victoria. Complicidad patronal-militar en la última dictadura argentina. Los casos de Acindar, Astarsa, Dálmine Siderca, Ford, Ledesma y Mercedes Benz. Suplemento especial de Engranajes. Buenos Aires: FETIA, 2006.

BASUALDO, Victoria; BARRAGÁN, Ivonne \& RODRÍGUEZ, Florencia. Dossier: La clase trabajadora durante la última dictadura militar argentina (19761983): apuntes para una discusión sobre la resistencia obrera. Buenos Aires: Comisión Provincial por la Memoria, 2010.

BISANG, Roberto. Factores de competitividad de la siderurgia argentina. Documento de Trabajo N. 32, Buenos Aires, CEPAL. 1989. 
BISIO, Raúl; KORINFELD, Silvia \& NEFFA, Julio. Mercado, innovación tecnológica y cambios organizacionales. Algunas transformaciones en el área metropolitana (1991-1995). Informe de Investigación No 3. Buenos Aires: CEIL- PIETTE, 1999.

BOURDIEU, Pierre. Como se hace una clase social. In: Poder, derecho y clases sociales. España: Desclée de Brouwer, 2000.

. Elsentido práctico. Madrid: Taurus Ediciones, 1991.

CANESQUI, Ana María. Os estudos de antropologia da saúde/doença no Brasil na década de 1990. Revista Ciência y Saúde Coletiva, 8 (1), p. 109-124, 2003.

CASTRO, Roberto. Salud y cotidianeidad: un análisis hermenéutico. In: GRIMBERG (Ed.) Experiencias y narrativas de padecimientos cotidianos. Miradas antropológicas sobre la salud, la enfermedad y el dolor crónico. Buenos Aires: Editorial Antropofagia, 2009.

CONRAD, Peter \& SCHNEIDER, Joseph W. Deviance and medicalization. From badness to sickness. Columbus-Ohio: Merrill Publishing Company, 1985.

CRAWFORD, Robert. The boundaries of the Self and the unhealthy Other: Reflections on health, culture and AIDS. Social Science \& Medicine. Vol. 38, № 10, 1994.

DE IPOLA, Emilio. La bemba. Acerca del rumor carcelario, Buenos Aires: Siglo XXI, 2005.

DEJOURS, Christophe. Psicodinámica del trabajo y vínculo social: Empresas y Psicología. Revista Actualidad Psicológica, n. 274, abril de 2000.

. Notas de trabajo sobre la noción de sufrimiento. In: _. Plaisir et souffrance dans le travail. Tradução de María José Acevedo Tomo 1. Ed. I'AOCIP, 1988. Disponível em: <http://www.catedras.fsoc. uba.ar>. Acesso em 21 de agosto de 2012.

DOUGLAS, Mary. Pureza y Peligro. Un análisis de los conceptos de contaminación y tabú. España: Siglo XXI, 1973.

ESPONDA, María Alejandra. La reestructuración productiva de los 90 en Propulsora Siderúrgica: debates, formas de organización y disputas de poder. In: BASUALDO, Victoria (coord.). La clase trabajadora argentina en el siglo XX: experiencias de lucha y organización. Buenos Aires: Editorial Cara o Ceca, 2011. . La carpeta negra de Mamá Propulsora. La reestructuración productiva desde la experiencia de los trabajadores. Tese de Licenciatura - Facultad de Humanidades y Ciencias Sociales, Departamento de Antropología Social, Universidad Nacional de Misiones, Misiones, Argentina, 2008.

FERNÁNDEZ ÁLVAREZ, María Inés. La productividad en cuestión. La formación de cooperativas en el proceso de recuperación de empresas en la Ciudad de Buenos Aires. In: CROSS, Cecilia \& BERGER, Matías (comp.) La producción del Trabajo Asociativo: Condiciones, Experiencias y Prácticas en la Economía Social. Buenos Aires: Ediciones CICCUS, 2010.

FONSECA, Claudia. Família, fofoca e honra. Etnografía de relaçôes de gênero e violência em grupos populares. Porto Alegre: Ed. UFRGS, 2000.

FOUCAULT, Michael. Historia de la Sexualidad - T. 1 La Voluntad de Saber. México: Siglo XXI Editores, 1991.

FREIDSON, Eliot. La profesión médica. Barcelona: Península, 1978.

GOOD, Byron. How Medicine Constructs its Objects. In: Medicine, Rationality and Experience. An Anthropological Perspective. Cambridge: Cambridge University Press, 1994.

GRIMBERG, Mabel. Demanda, negociación y salud. Antropología social de las representaciones y prácticas de trabajadores gráficos 1984-1990. Buenos Aires: Oficina de Publicaciones del CBC, Universidad Nacional de Buenos Aires, 1997.

GUEDES, Simoni L. Jogo de Corpo. Um estudo de construçăo social de trabalhadores. Niterói: EdUFF, 1997.

GUNDER FRANK, Andre. Después de la "reaganomía" y el "thatcherismo", ¿qué?. Cuadernos Politicos, número 31, México D.F.: ed. Era, p. 5-16, 1982.

HARVEY, David. La condición de la Posmodernidad. Buenos Aires: Amorrortu, 1998.

JABAZZ, Marcela Isabel. Nuevas reglas de juego de la negociación y nuevas formas de organización del trabajo: estrategias patronales y sindicales frente a la reconversión. CEIL-PIETTE. Documento de Trabajo No 36. 1994. Disponível em: <http://www.monografias. com/trabajos902/reconversion-siderurgica-estrategias/ reconversion-siderurgica-estrategias.shtml. Acesso em 20 de outubro de 2010.

LAURELL, Asa Cristina. Crisis y salud en America Latina. Cuadernos Politicos, numero 33, Mexico: Editorial Era, p. 32-45, 1982.

. Proceso de trabajo y salud. Cuadernos Políticos. Número 17, México: Editorial Era, p.59-79, 1978.

LEITE LOPES, José Sergio. El vapor del diablo: El trabajo entre los obreros del azúcar. Traducción de Andrea Roca. Buenos Aires: Editorial Antropofagia, 2011.

LOCK, Margaret. Cultivating the body: anthropology and epistemologies of bodily practice and knowledge. Annual Review of Anthropology. v. 22, p. 133-155, 1993.

MEIKSINS WOOD, Ellen. El concepto de clase en E.P. Thompson. Pensamiento Iberoamericano, Madrid: ICI/CEPAL, 1984. 
MENÉNDEZ, Eduardo. Biologización y racismo en la vida cotidiana. Alteridades, 11 (21): p. 5-39, 2001. - Morir de alcohol. México: Ediciones de la Casa Chata, 1990.

- Modelo médico, salud obrera y estrategias de acción del sector salud. Revista Nueva Antropología, vol. VIII, número 029. Universidad Nacional Autónoma de México, México, p. 49-63, 1986.

MOLINERO, Ángel. Los oligurkas del acero. Livro inédito. Versão original mimeografada.

NEEDHAM, R. Introduction. In: DURKHEIM, Émile \& MAUSS, Marcel. Primitive classification. Chicago: University of Chicago Press, 1963.

NOCHTEFF, Hugo J. La política económica en la Argentina de los noventa. Una mirada de conjunto. Revista Época. No 1, Buenos Aires, 1999.

NOVICK, Martha. La transformación de la organización del trabajo. In: DE LA GARZA TOLEDO, Enrique (comp). Tratado Latinoamericano de sociología del trabajo. México: Editorial FCE, 2000.

RIBEIRO, Gustavo Lins. El capital de la esperanza. La experiencia de los trabajadores en la construcción de Brasilia. Buenos Aires: Editorial Antropofagia, 2006.

RODRIGUEZ, Florencia. Lucha de clases, conciencia y política. El caso de Propulsora Siderúrgica 19731975. In: XIII JORNADAS INTERESCUELAS DEPARTAMENTOS DE HISTORIA, Catamarca, Argentina, 2011. CD-ROM.

SÁNCHEZ, Ligia \& YANES, Leopoldo. El abordaje de la salud de los trabajadores en el escenario de reajuste económico, la reconversión industrial y los cambios tecnológicos. Salud de los Trabajadores. Venezuela: Volumen 3, n. 1, 1995.

SANTARCÁNGELO, Juan \& SCHORR, Martín. Desempleo y precariedad laboral en la Argentina durante la década de los noventa. Revista Estudios del Trabajo. n. 20, Buenos Aires: ASET, 2000.
SAYER, Andrew. Nuevos desarrollos en la fabricación: el sistema 'justo a tiempo'. In: FINKEL, Lucila. La organización social del trabajo. Madrid: Ediciones Pirámide, 1997.

SCHEPER-HUGHES, Nancy \& LOCK, Margaret. The mindful body. A prolegomenon to future work in Medical Anthropology. Medical Anthropology Quarterly. New Series, n. 1, 1987.

THOMPSON, Edward Palmer. Tradición, revuelta y conciencia de clase. Barcelona: Ed. Crítica, 1989a. - La formación de la clase obrera en Inglaterra. Barcelona: Ed. Crítica, 1989b.

\section{Agradecimentos}

Agradezco especialmente la lectura atenta y recomendaciones sobre el texto de Mabel Grimberg, Carolina Diez, Victoria Basualdo y Florencia Rodríguez; el intercambio constante dentro del "Programa Estudios del trabajo, movimiento sindical y organización industrial", perteneciente al Área de Economía y Tecnología de FLACSO; los comentarios y discusiones promovidas por Gloria Rodríguez y Diana Antonaz. Por último, mi agradecimiento al PPAS/UNaM, por el valioso espacio de formación académica y especialmente a Leopoldo Bartolomé por su incesante acompañamiento.

\section{autora María Alejandra Esponda}

Licenciada en Antropología Social / PPAS, UNam, FLACSO - Conicet

Recebido em 30/03/2012

Aprovado para publicação em 01/10/2012 